\title{
A European inter-laboratory trial to evaluate the performance of three serological methods for diagnosis of Mycoplasma bovis infection in cattle using latent class analysis
}

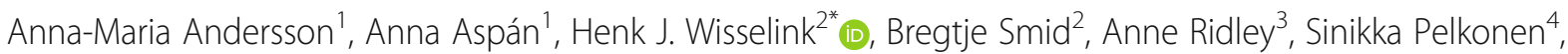 \\ Tiina Autio ${ }^{4}$, Klara Tølbøll Lauritsen ${ }^{5}$, Jane Kens $\varnothing^{5}$, Patrice Gaurivaud ${ }^{6}$ and Florence Tardy ${ }^{6}$
}

\begin{abstract}
Background: Mycoplasma bovis (M. bovis) is an emerging bovine pathogen, leading to significant economic losses in the livestock industry worldwide. Infection can result in a variety of clinical signs, such as arthritis, pneumonia, mastitis and keratoconjunctivitis, none of which are M. bovis-specific. Laboratory diagnosis is therefore important. Serological tests to detect $M$. bovis antibodies is considered an effective indicator of infection in a herd and often used as a herd test. Combined with clinical judgement, it can also be used to implement control strategies and/or to estimate the disease prevalence within a country. However, due to lack of harmonisation of approaches to testing, and serological tests used by different laboratories, comparisons of prevalence data between countries is often difficult. A network of researchers from six European countries designed and participated in an interlaboratory trial, with the aim of evaluating the sensitivity (Se) and specificity (Sp) of two commercially available ELISA tests (ID Screen ${ }^{\oplus}$ ELISA (IDvet) and BIO K302 ELISA (BIO-X Diagnostics)) for diagnosis of M. bovis infection. Each laboratory received a blinded panel of bovine sera and tested independently, according to manufacturer's instructions. Western blot analyses (WB) performed by one of the participating laboratories was used as a third diagnostic test in the statistical evaluation of $S e$ and $S p$ values using latent class analysis.

Results: The Se of WB, the ID Screen ${ }^{\oplus}$ ELISA and the BIO K302 ELISA were determined to be $91.8,93.5$ and 49.1\% respectively, and corresponding Sp of the three tests were 99.6, 98.6 and 89.6\%, respectively.

Conclusions: The present study is, to our knowledge, the first to present an inter-laboratory comparison of the BIO K302 ELISA and the ID Screen ${ }^{\oplus}$ ELISA. Based on our results, the ID Screen ${ }^{\circledast}$ ELISA showed high consistency with WB and performed with higher precision and accuracy than the BIO K302 ELISA.
\end{abstract}

Keywords: Mycoplasma bovis cattle, Inter-laboratory trial, ELISA, Western blot, Latent class analysis

\footnotetext{
* Correspondence: henk.wisselink@wur.nl

${ }^{2}$ Wageningen Bioveterinary Research, P.O. Box 65, 8200, AB, Lelystad, the

Netherlands

Full list of author information is available at the end of the article
}

(C) The Author(s). 2019 Open Access This article is distributed under the terms of the Creative Commons Attribution 4.0 International License (http://creativecommons.org/licenses/by/4.0/), which permits unrestricted use, distribution, and reproduction in any medium, provided you give appropriate credit to the original author(s) and the source, provide a link to the Creative Commons license, and indicate if changes were made. The Creative Commons Public Domain Dedication waiver (http://creativecommons.org/publicdomain/zero/1.0/) applies to the data made available in this article, unless otherwise stated. 


\section{Background}

Mycoplasma bovis has emerged as a pathogen of increasing importance in many industrialised countries around the world, causing significant economic and production losses particularly in the beef and dairy industries [1-4]. Infection with $M$. bovis is associated with a variety of clinical manifestations. In calves, the infection can present as respiratory disease, arthritis and otitis media. In adult cattle, pneumonia, mastitis, otitis media, and reproductive problems have been observed [1, 4, 5]. Since none of these clinical signs are pathognomonic, definitive and accurate diagnosis requires laboratory confirmation. This is important for implementation of control strategies such as enabling immediate separation of infected livestock and early administration of appropriate treatment, as the spread of disease is difficult to contain once present on a farm $[6,7]$.

Bacterial cultural identification has traditionally been considered the gold standard method for M. bovis, but is labour intensive and time-consuming [8]. Interpretation of culture results can also be hampered by the intermittent shedding of $M$. bovis, sub-optimal sampling and transportation procedures or by antimicrobial treatment prior to sampling $[1,7]$. PCR-based detection of $M$. bovis has been increasingly favoured over the past two decades to overcome difficulties associated with cultural diagnosis. However, PCR methods are also highly dependent on the organism being shed at the time of sampling, as well as efficiency of DNA extraction, particularly in presence of inhibitors, as well as specific primers and probes with sensitive detection $[7,9]$.

With demand for rapid, inexpensive and convenient tests, serological tests for herd level testing have been developed, and used widely, over several decades. These methods are designed to retrospectively detect $M$. bovis antibodies in cattle that have been exposed to the pathogen and thus have mounted a detectable humoral immunological response (usually from 2 to 3 weeks after infection) [7]. The immunological response is theoretically measurable in plasma, serum or milk although effectiveness of detection may vary depending on sample type and format of the test [7]. Used alone, these serological tests enable rapid and cost-effective screening for the presence of infection or demonstration of absence of infection in a herd. However, for optimal monitoring of $M$. bovis infection status in a herd, a combination with other diagnostic methods is recommended [6].

Several serological diagnostic tests exist, each having their benefits and limitations. Western blot analysis (WB; also known as immunoblotting) has been considered a robust and specific method, suitable as a confirmatory test $[10,11]$, but it requires preparation of a suspension of antigenic proteins from an appropriate control strain that is then electrophoresed and blotted onto membranes before being ready to test serum samples. Therefore, the method is time consuming and not suitable for screening of large numbers of samples. For the routine laboratory workflow, use of enzyme-linked immunosorbent assays (ELISA) is often the preferred method.

The choice of the antigen(s) used in the ELISA assays is important as it must be (i) both specific for, and universally present in, all strains of the targeted bacterium, (ii) persistently expressed during the infection, and (iii) recognised by the host humoral response independently of the clinical outcome of the infection [10-12]. Antigenic variation in M. bovis is well recognised and many of the originally developed assays comprise whole cell antigen [13]. In the past decade, ELISA tests based on antigens that are expressed in Escherichia coli by recombinant DNA technology have been developed [12, 14-17]. However, in the absence of commercially standardised production methods and controls, variability associated with reproducibility of antigen coating when in-house assays are transferred to other laboratories can make comparisons problematic $[8,9]$. Owing to pre-validated performance and general ease of use, commercially produced $M$. bovis ELISAs are therefore attractive and are increasingly used by diagnostic laboratories globally.

Although several $M$. bovis serological studies have been conducted, many studies report results of development of in-house assays [14, 16, 18, 19], with fewer focused on comparison of methods [10, 12], and to our knowledge none has focused on the inter-laboratory performance of these assays. Two commercially produced ELISA kits that are used internationally for the detection of $M$. bovis antibodies in cattle have featured predominantly in previously reported studies; BIO K302 (Bio-X Diagnostics, Rochefort, Belgium) and Bovicheck (Biovet Inc., Quebec, Canada), with the latter not currently used by veterinary laboratories in Europe [12, 16, 17, 20-22]. Another commercial ELISA for $M$. bovis which also uses plates coated with a purified $M$. bovis recombinant antigen has recently become available; the ID Screen ${ }^{\bullet}$ ELISA (IDvet, Grabels, France). This ELISA has, to our knowledge, not previously been evaluated by diagnostic laboratories.

The aim of the study was to evaluate the sensitivity $(\mathrm{Se})$ and specificity $(\mathrm{Sp})$ of two commercial ELISA kits (ID Screen ${ }^{\circledR}$ ELISA from IDvet and BIO K302 ELISA from BIO-X Diagnostics) for serodiagnosis of $M$. bovis in cattle by means of an inter-laboratory comparison. WB was used as a third method to enable statistical evaluation using latent class analysis (LCA).

\section{Results}

Number of positive and negative serum samples Western blot analysis

Of the 180 serum samples, analysed by WB, 77 (43\%) exhibited a banding pattern consistent with $M$. bovis 
infection and were categorised as positive, while 103 (57\%) were negative, by virtue of the absence of the 50 and $85 \mathrm{kDa}$ indicative immunogenic bands. This included all 90 serum samples from northern Sweden. The positive serum samples all originated from the highprevalence area (Fig. 1; Table 1).

\section{ELISA I: ID screen ${ }^{\circledast}$ ELISA}

Forty-four percent of the serum samples had an S/P \% of $\geq 60 \%$ and were categorised as seropositive using the cut-off recommended by the manufacturer. The proportion of positive test results varied between 43 and $46 \%$ for the six different laboratories in the two different runs (Table 2). For the different populations, $87 \%$ of the samples from the high-prevalence area and $0.4 \%$ of the samples from the low-prevalence area were seropositive using this test (Table 3 ).

\section{ELISA II: the BIO K302 ELISA}

With the BIO K302 ELISA, 29\% of the samples had an S/P \% > 37\% and were categorised as seropositive using the cut-off recommended by the manufacturer. The proportion of positive test results varied between 16 and $66 \%$ for the six different laboratories in the two different runs (Table 2). Looking at the different populations, $46 \%$ of the samples from the high-prevalence area and $12 \%$ of the samples from the low-prevalence area were seropositive using the BIO K302 ELISA (Table 3).

\section{Statistical analysis}

\section{Precision of the two ELISA tests}

For the ID Screen ${ }^{\circ}$ ELISA, the categorisation between the two duplicate runs for each serum sample at each laboratory was generally preserved. However, on eight occasions, affecting six of the individual serum samples analysed $(n=180)$ and five of the laboratories, the categorisation differed between the first and the second test run. Data are provided in a table in Additional file 1.

For the BIO K302 ELISA, the categorisation was much less preserved between the two duplicate runs and on 64 occasions (affecting 56 out of the 180 serum samples, and all laboratories) the categorisation differed between the first and second run. Data are provided in a table in Additional file 1.

\section{Accuracy of the three diagnostic tests}

The accuracy of WB and the two ELISA kits were estimated by LCA using both informative priors as well as uniform distribution and estimating co-variances of the three diagnostic tests. All LCA models converged according to the diagnostic plots. The difference between the model using informative priors and the model using uniform distribution was minor but both models are presented in Table 4 for comparison. In general, the covariances between the three tests for both $S e$ and $S p$ were negligible $(\leq 0.5 \%)$ apart from between WB and the ID Screen ${ }^{\circ}$ ELISA $\left(\operatorname{cov}_{\mathrm{Se}}=5.4 \%\right.$; model with informative

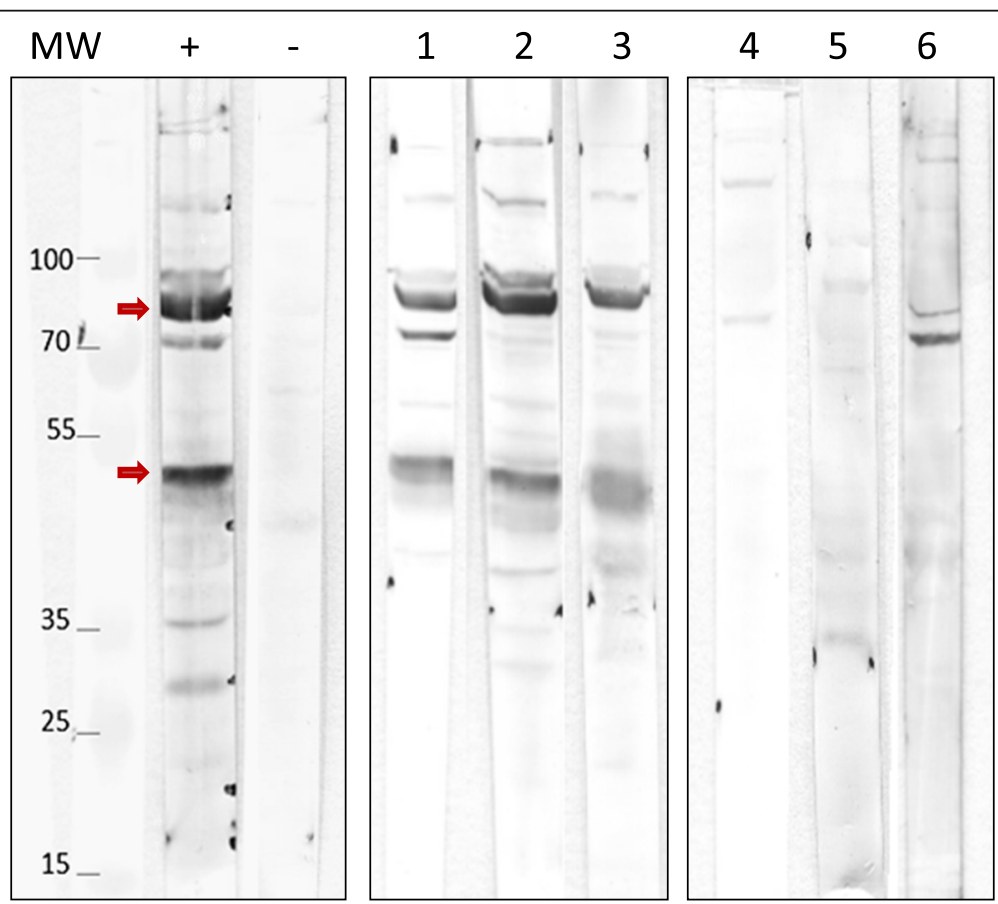

Fig. 1 Western blot analysis (WB) of the reactivity of different sera with M. bovis strain L15762. MW, molecular weight (kDa); "+" and "-"are positive and negative controls, respectively. Illustration of the banding patterns obtained for positive (lanes 1 to 3 ) and negative sera (lanes 4 to 6 ). The arrows on the left point toward the two main bands expected to be present in all positive sera 
Table 1 Results of the western blot analysis (WB) as performed by laboratory 3 on the 180 serum samples. Serum samples originated from cattle populations where $M$. bovis is known to be prevalent (the high-prevalence area: Finland, France, the Netherlands and the United Kingdom) and from a cattle population which was considered highly unlikely to have been exposed to M. bovis (the low-prevalence area: northern Sweden)

\begin{tabular}{llll}
\hline \multirow{2}{*}{ WB result } & \multicolumn{2}{l}{ Number (\%) of tests } & \\
\cline { 2 - 4 } & High prevalence area & Low prevalence area & All samples \\
\hline Positive & $77(85.5 \%)$ & $0(0 \%)$ & $77(42.8 \%)$ \\
Negative & $13(14.5 \%)$ & $90(100 \%)$ & $103(57.2 \%)$ \\
All & 90 & 90 & 180 \\
\hline
\end{tabular}

priors). Therefore, only the model assuming co-variance between WB and the ID Screen ${ }^{\circ}$ ELISA is presented in Table 4. The $\mathrm{Se}$ of $\mathrm{WB}$, the ID Screen ${ }^{\circ}$ ELISA and the BIO K302 ELISA was estimated to be $91.8,93.5$ and $49.1 \%$, respectively. $S p$ was $99.6,98.6$ and $89.6 \%$ respectively, based on the model using informative priors. With regards to the non-overlapping posterior credibility intervals (PCI), both WB and the ID Screen ${ }^{\circ}$ ELISA had significantly higher $S e$ and $S p$ than the BIO K302 ELISA (Table 4).

\section{Discussion}

With few commercial $M$. bovis ELISAs available, several studies have applied in-house ELISAs to detect $M$. bovis antibodies in serum and milk [12, 14, 16, 18, 23, 24]. Initially, we used our set of sera to evaluate an in-house indirect ELISA using the MilA protein as antigen [17]. High intra-laboratory variation did not permit meaningful comparisons between the six participating laboratories (data not shown). For similar method transfer concerns, an in-house ELISA using a whole cell antigen preparation which has been in use for several years by one of the participating laboratories [13] was also not included for inter-laboratory comparison in this study.
Instead, two available commercial ELISA systems, one of which has become widely used internationally, were chosen. A whole cell WB was used as a third diagnostic method to allow latent class statistical analysis as the information required to clinically and microbiologically confirm $M$. bovis infection was not available for all the serum samples included in the study.

To our knowledge, this is the first study to present an inter-laboratory comparison of the BIO K302 ELISA (BioX Diagnostics) and the ID Screen ELISA (IDVet) for serological detection of $M$. bovis infections in cattle. Overall, the results demonstrated high $\mathrm{Se}$ and high $\mathrm{Sp}$ for the ID Screen ${ }^{\circ}$ ELISA, while the same values for the BIO K302 ELISA were significantly lower, based on nonoverlapping 95\% PCIs (Table 4). These findings are broadly in agreement with previous studies which report a lower $\mathrm{Se}$ for the BIO K302 ELISA compared with other ELISAs [12, 17, 21]. In addition, Schibrowski et al. (2018) reported a similar Se (47\%) for the BIO K302 ELISA while using the manufacturer's recommended cut-off and analysing serum samples from exposed and non-exposed cattle from three different countries $[10$, 11].

The difference in diagnostic accuracy of the two ELISAs was reflected in the percentage of seropositive cattle from the high-prevalence area where there was a difference in proportion of positive tests obtained, varying from 87.2 to $45.9 \%$, depending on whether the ID Screen $^{\circ}$ ELISA or the BIO K302 ELISA was used. By comparison, WB identified $83.5 \%$ of the samples from the high-prevalence area as seropositive for M. bovis. The difference in accuracy was also observed for the categorisation of the serum samples from the lowprevalence area. Only WB categorised all samples from the low-prevalence area as seronegative for $M$. bovis. For the ID Screen ${ }^{\circ}$ ELISA, $0.4 \%$ of the serum samples from northern Sweden were categorised as positive for $M$. bovis, but for the BIO K302 ELISA the corresponding

Table 2 The percentage of seropositive serum samples $(n=180)$ for M. bovis infections in two duplicate runs of the ID Screen ${ }^{\oplus}$ ELISA (using a cut-off for the S/P coefficient $\geq 60 \%$ as suggested by the manufacturer together with the kit) and the BIO K302 ELISA (using a cut-off for the S/P coefficient $>37 \%$ as suggested by the manufacturer together with the kit) at the six laboratories participating in the ring trial

\begin{tabular}{|c|c|c|c|c|c|c|}
\hline \multirow[b]{2}{*}{ Lab no. } & \multicolumn{3}{|c|}{ ID Screen ${ }^{\circledast}$ ELISA } & \multicolumn{3}{|c|}{ BIO K302 ELISA } \\
\hline & $\begin{array}{l}\text { Duplicate } 1 \\
\text { (\%) }\end{array}$ & $\begin{array}{l}\text { Duplicate } 2 \\
\text { (\%) }\end{array}$ & Mean of the two duplicates (\%) & $\begin{array}{l}\text { Duplicate } 1 \\
\text { (\%) }\end{array}$ & $\begin{array}{l}\text { Duplicate } 2 \\
\text { (\%) }\end{array}$ & Mean of the two duplicates (\%) \\
\hline 1 & 43.3 & 43.3 & 43.3 & 20.6 & 20.6 & 20.6 \\
\hline 2 & 45.0 & 44.4 & 45.0 & 54.4 & 65.6 & 61.1 \\
\hline 3 & 42.2 & 43.3 & 42.8 & 38.9 & 26.7 & 32.8 \\
\hline 4 & 46.1 & 45.0 & 45.6 & 23.9 & 23.3 & 23.3 \\
\hline 5 & 43.3 & 43.3 & 43.3 & 16.1 & 16.1 & 16.7 \\
\hline 6 & 42.8 & 42.2 & 42.8 & 19.4 & 20.0 & 20.0 \\
\hline All & 43.8 & 43.6 & 43.8 & 28.9 & 28.7 & 29.1 \\
\hline
\end{tabular}


Table 3 Results of the ID Screen ${ }^{\circledR}$ ELISA and the BIO K302 ELISA as performed by the six laboratories each testing the same 180 serum samples. The mean of the two duplicate runs was used to categorise the sample as seropositive or seronegative using a cutoff for the S/P coefficient suggested by the manufacturer together with the kit ( $\geq 60 \%$ for the ID Screen ${ }^{\circledast}$ ELISA, and $>37 \%$ for the BIO K302 ELISA). Serum samples originated from cattle populations where M. bovis is known to be prevalent (the high-prevalence area: Finland, France, the Netherlands and the United Kingdom) and from a cattle population which was considered highly unlikely to have been exposed to M. bovis (the low-prevalence area: northern Sweden)

\begin{tabular}{lllllll}
\hline \multicolumn{7}{c}{ Number (\%) of ELISA tests } \\
\cline { 2 - 6 } & ID Screen ${ }^{\circledast}$ ELISA & & & \\
\hline ELISA result & High prevalence area & Low prevalence area & All samples & High prevalence area & Low prevalence area & All samples \\
Positive & $471(87.2)$ & $2(0.4)$ & $473(43.8)$ & $248(45.9)$ & $64(11.9)$ & $312(28.8)$ \\
Negative & $69(12.8)$ & $538(99.6)$ & $607(56.2)$ & $292(54.1)$ & $476(88.1)$ & $768(71.1)$ \\
All & 540 & 540 & 1080 & 540 & 540 & 1080 \\
\hline
\end{tabular}

percentage was substantially higher at $12 \%$. These samples were included in the study since they originate from a population of cattle highly unlikely to ever have been exposed to M. bovis [25].

It has previously been suggested that the manufacturer's recommended cut-off of $37 \%$ for the BIO K302 ELISA samples is too low, and a cut-off of $50 \%$ would reduce the false positive results [21]. However, the study in question was based on bulk tank milk samples and cannot be directly extrapolated to serum diagnostics. Further, in our study, for the set of sera from the highprevalence area, the percentage of seropositive samples as well as the $S e$ value obtained were both markedly lower for the BIO K302 ELISA than WB and ID Screen ${ }^{\oplus}$ ELISA. Raising the cut-off to 50\% would result in even lower Se for the BIO K302 ELISA and such changes should not be attempted without prior optimisation of the ELISA kit.

To assess the precision of the three tests and allow for better comparison between the six laboratories,

Table 4 Posterior median and 95\% posterior credibility interval (95\% PCI) of sensitivity and specificity for western blot analysis (WB), the ID Screen ${ }^{\oplus}$ ELISA and the BIO K302 ELISA obtained from latent class analysis assuming conditional independence between tests and using informative or uniform priors

\begin{tabular}{|c|c|c|c|c|}
\hline & \multicolumn{2}{|c|}{ Informative priors } & \multicolumn{2}{|c|}{ Uniform priors } \\
\hline & Median & $95 \% \mathrm{PCl}$ & Median & $95 \% \mathrm{PCl}$ \\
\hline \multicolumn{5}{|l|}{ Sensitivity \& specificity } \\
\hline Sensitivity WB & 0.918 & {$[0.879 ; 0.950]$} & 0.935 & {$[0.892 ; 0.973]$} \\
\hline Specificity WB & 0.996 & {$[0.987 ; 1.00]$} & 0.999 & {$[0.993 ; 1.00]$} \\
\hline Sensitivity ID Screen ${ }^{\circledast}$ & 0.935 & {$[0.898 ; 0.965]$} & 0.952 & {$[0.910 ; 0.990]$} \\
\hline Specificity ID Screen ${ }^{\oplus}$ & 0.986 & {$[0.976 ; 0.994]$} & 0.994 & {$[0.985 ; 0.999]$} \\
\hline Sensitivity BIO K302 & 0.491 & {$[0.447 ; 0.535]$} & 0.493 & {$[0.448 ; 0.538]$} \\
\hline Specificity BIO K302 & 0.896 & {$[0.872 ; 0.918]$} & 0.879 & {$[0.849 ; 0.905]$} \\
\hline \multicolumn{5}{|l|}{ Covariances } \\
\hline $\left.\operatorname{Cov}_{\mathrm{Se}\left(W B^{*} \text { IDScreen }\right.}{ }^{\bullet}\right)$ & 0.054 & {$[0.024 ; 0.072]$} & 0.038 & {$[0.005 ; 0.074]$} \\
\hline $\operatorname{Cov}_{S p\left(W B^{*} \mid D S c r e e n^{\oplus}\right)}$ & 0.008 & {$[0.000 ; 0.018]$} & 0.000 & {$[0.000 ; 0.004]$} \\
\hline
\end{tabular}

duplicate runs were performed for both the ELISA tests. For the ID Screen ${ }^{\circledR}$, results between the duplicate runs were very similar, with only six samples differing in categorisation at one or two laboratories. For the BIO $\mathrm{K} 302$, on the other hand, $31 \%$ of the samples differed in categorisation between the two runs, especially at two laboratories (these data were not specifically centred around the cut-off nor pair-wise close to each other; see data in Additional file 1). Use of the same batch of each ELISA kit by all participating laboratories for the study was designed to negate effects of batch variability for each of the ELISAs. Moreover, technical issues that may have contributed to the observed differences for the repeated testing of samples might reasonably have been expected to affect both tests similarly, which was not the case here. Unfortunately, the study design did not enable further evaluation of this unexpected variation, specifically whether the source was associated with the robustness of the assay per se or at the local laboratory level.

One of the ELISA systems included in this study, BIO K302, has previously been evaluated on BTM samples $[21,26,27]$ as well as on serum samples [17, 27]. BTM samples can, if the ELISA is sensitive and specific, be an excellent tool for herd diagnosis of several systemic infections in dairy herds [28-30]. However, previous studies have found that this is more challenging for M. bovis; while cattle suffering from $M$. bovis mastitis have been found to have high antibody titres both in milk and serum Moreover, the serological status of young stock may not be well reflected by testing of BTM samples, and milk antibody measurements only have diagnostic utility for cows with mastitis and are unsuitable for other clinical manifestations of $M$. bovis infections [31]. Information demonstrating correlation in both matrices is still lacking and warrants further study. Thus, in herds where no clinical mastitis or no lactating cows are present, ELISA analysis must rely on serum sampling instead of milk samples. For this reason, it is crucial that the chosen ELISA method has been validated for detection of antibodies in serum with high accuracy and high 
precision. Since the ID Screen ${ }^{\circ}$ ELISA showed a higher precision and accuracy than the BIO K302 ELISA in this study, the ID Screen ${ }^{\circ}$ ELISA seems promising as a test for reliable determination of infection status for control programs, disease management and research purposes in the future. However, further evaluation of the ID Screen ${ }^{\circ}$ ELISA under field conditions, on other sample types, such as milk in animals of known disease status, and comparative microbiological testing is warranted. In addition, a longitudinal study similar to that described by Petersen et al., [31], evaluating the antibody response between individual animals, as well as paired samples from the same individual, would be of great value in the future.

Despite reported failures of antimicrobial chemotherapy to control $M$. bovis infection, there are currently no effective vaccines available against $M$. bovis in Europe and the reported performance of the vaccines currently licensed in the USA is rather poor [1,32]. Efforts are ongoing to identify antigens that will induce a protective immunity. Antigenic proteins conserved across different strains are most likely to be targeted as potential $M$. bovis vaccine candidates and hence are often similar to proteins of greatest interest as targets for immunodiagnostic tools. A future challenge facing producers of serological tests for $M$. bovis will be to ensure accurate detection of serological response to ensure effective discrimination between vaccinated and naturally infected cattle. It also highlights that despite limited new developments in $M$. bovis serological testing, regular assessment of the performance of available serological diagnostic tools is required to take into account minor changes to test components and the diversity and evolution of strains causing infection worldwide. Future developments should also consider the potential existence of different vaccination strategies.

\section{Conclusions}

With increased awareness of the importance of $M$. bovis in bovine respiratory disease and mastitis, there is growing requirement for readily available, reproducible serological assays offering high precision and accuracy for diagnosis of $M$. bovis infection in cattle herds globally. Differences in the performance of the two commercially available ELISAs demonstrates that limitations exist with the use of such tests and highlights the importance undertaking regular assessment of performance, even when commercial tests are being used. Using a test with a high $S e$ and $S p$ proven by inter-laboratory comparison, such as the ID Screen ${ }^{\circ}$ ELISA, can provide improved knowledge on the prevalence of $M$. bovis in different cattle populations. Through a combination of validated diagnostic tools, well assessed sample strategies and information on clinical symptoms on herd and animal level, we can improve monitoring of $M$. bovis in cattle herds and enhance our understanding of the epidemiology of $M$. bovis infections.

\section{Methods \\ Participating institutes}

Six Animal Health Institute laboratories from six different European countries participated in the M. bovis ELISA ring trial: the Animal and Plant Health Agency (APHA), UK; the National Veterinary Institute, Technical University of Denmark (DTU), Denmark; the Finnish Food Safety Authority (Evira), Finland; the French Agency for Food, Environmental and Occupational Health \& Safety (ANSES), France; the National Veterinary Institute (SVA), Sweden and the Wageningen Bioveterinary Research (WBVR), The Netherlands. The laboratories were anonymously allocated a number 1 to 6.

\section{Origin and distribution of serum samples}

For evaluation of the diagnostic tests, a serum panel comprising 180 cattle serum samples was collated. Half of the panel $(n=90)$ comprised sera derived from animals from $M$. bovis infected farms in France, Finland, the UK and the Netherlands where $M$. bovis is known to be prevalent $[6,33-35]$. This area will be hereafter called the "high-prevalence area" (Table 5). The farms from which the samples were drawn were located in different geographical areas within each country and, where information was available, originated from cattle with different disease manifestations including respiratory disease, mastitis and arthritis. Most, but not all, of these sera had previously been determined as positive for $M$. bovis by the tests commonly used by the respective laboratories and from clinical information from the herd. Additionally, where available PCR data confirming the presence of the organism by PCR was used to inform selection. A small number of samples from the high-prevalence area that had previously tested negative, or were only weakly positive but taken from herds that included animals with moderate-to-high titres, were also included. The remaining 90 serum samples represented a cattle population from northern Sweden, where M. bovis has never been diagnosed, and is therefore considered highly unlikely to have been exposed to M. bovis infection [25]. This area will hereafter be known as the "low-prevalence area" (Table 5).

All sera were sent to laboratory 4 where they were randomised, aliquoted into individual tubes, labelled with numbers 1 to 180 and sent to each participating laboratory for blinded testing (including laboratory 4). The samples were dispatched on dry ice and each laboratory stored the serum samples at, or below, $-20^{\circ} \mathrm{C}$ until analysis. Laboratory 3 received a supplemental volume of each serum sample for WB. 
Table 5 Country of origin, number of samples, clinical disease manifestation, age group of cattle sampled, number of farms sampled, year of collection as well as prevalence area categorisation based on anticipated M. bovis seroprevalence for the 180 serum samples used in this study

\begin{tabular}{lllllll}
\hline Country & Number of samples & Clinical signs & Age & Number of farms & Year(s) of collection & Prevalence area \\
\hline Finland & 30 & Mastitis & Various & 3 & 2015 to 2016 & High \\
France & $22^{\mathrm{a}}$ & Pneumonia & Veal calves & 9 & 2014 & High \\
UK & 28 & Various & Various & 18 & 2013 to 2017 & High \\
The Netherlands & 10 & Pneumonia & Veal calves & 10 & 2014 & High \\
Sweden & $90^{\mathrm{a}}$ & None & NA & NA & 2013 & Low \\
Total no samples & 180 & & & & &
\end{tabular}

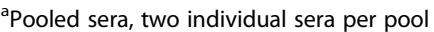

${ }^{\mathrm{b}}$ Samples from infected animals from farms with few mastitis cases

$N A$ data not available

\section{Three serological methods}

\section{Western blot analysis}

M. bovis strain L15762, belonging to the main subtype currently circulating in France [33, 34], was cultivated at $37^{\circ} \mathrm{C}$ for $48 \mathrm{~h}$ in modified PPLO broth [36]. Cells were harvested by centrifugation at $12,000 \mathrm{x}$ g for $20 \mathrm{~min}$ at $4{ }^{\circ} \mathrm{C}$, washed three times in phosphate buffered saline (PBS) and protein content estimated using the Pierce BCA protein assay kit (ThermoFisher Scientific, Illkirch, France). Twenty $\mu \mathrm{g}$ of protein, suspended in Laemmli buffer, was loaded per well on a miniprotean TGX $10 \%$ gel (BioRad, Marnes-La-Coquette, France) for SDSPAGE analysis. Electrophoresis was performed at $125 \mathrm{~V}$ until the bromophenol blue reached the bottom of the gel. Subsequent blotting and immuno-detection steps were conducted as previously described [37]. For the positive control, serum from a veal calf with respiratory disease, determined to be positive for $M$. bovis following real-time PCR (MPBO50 kit from ThermoFisher Scientific) and cultural examination of nasal swabs and BALF, sampled at day 21 after clinical onset, was used. The negative control originated from a pool of sera from two veal calves taken prior to introduction to a feedlot (day 0 ), when calves were of approximately 15 days old. Both animals tested negative by an M. bovis-specific PCR [38], with the herd confirmed seronegative (ELISA BIO K302) at day 0 and again 40 days later). A serum sample was considered positive if its WB profile contained two discrete immunogenic bands at 50 and $85 \mathrm{kDa}$ (Fig. 1).

\section{ELISA I: ID screen ${ }^{\circledR}$ ELISA}

Serum samples were analysed with the ID Screen ${ }^{\circ} \mathrm{Myco-}$ plasma bovis indirect ELISA kit according to the instructions of the manufacturer (IDvet, Grabels, France). All laboratories used the same manufacturers' batch of ELISA kit and all reagents, including positive and negative controls, were provided by the manufacturer as a part of the kit. The following procedures were followed by all participating laboratories. The serum samples were thawed and diluted 1:40 in dilution buffer in the pre- coated plates. Positive and negative controls were added in duplicate to each plate. After incubation for $45 \mathrm{~min}$ at room temperature ( $\mathrm{RT}$, recommended by the manufacturer to be $21+/-5^{\circ} \mathrm{C}$ ), each well was washed three times with wash solution prior to addition of $100 \mu \mathrm{L}$ anti-bovine horseradish peroxidase (HRP) conjugate. After $30 \mathrm{~min}$ incubation at $\mathrm{RT}$, the plates were again

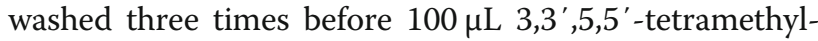
benzidine (TMB) substrate solution was added to each well. The plates were incubated $15 \mathrm{~min}$ in the dark at RT before the reaction was stopped by adding $100 \mu \mathrm{L}$ stop solution. The optical density (OD) was measured at $450 \mathrm{~nm}$. The test was considered valid if the mean value of the positive control was greater than 0.350 , and the ratio between the mean positive control and the mean negative control was greater than three. All serum samples were run in duplicate on separate plates and for each serum sample in each run the sample-to-positive percentage (S/P \%) was calculated using the formula:

$$
\begin{aligned}
& \mathrm{S} / \mathrm{P} \%=\left(\left(\mathrm{OD}_{\text {sample }}-\mathrm{OD}_{\text {mean negative control }}\right) /\right. \\
& \left.\left.\quad \mathrm{OD}_{\text {mean positive control }}-\mathrm{OD}_{\text {mean negative control }}\right)\right) \times 100
\end{aligned}
$$

The S/P \% for each sample for each run was used to categorise the sample as positive or negative using the cut-off value provided by the manufacturer (positive if the $\mathrm{S} / \mathrm{P} \% \geq 60 \%$ ).

\section{ELISA II: the BIO K302 ELISA}

Serum samples were analysed with the Mycoplasma bovis BIO K302 according to manufacturers' instructions (Bio-X Diagnostics, Rochefort, Belgium). All laboratories used the same batch of ELISA kit and all reagents, including positive and negative controls, were provided as part of the kit. The following procedure was used. The serum samples were thawed and diluted 1:100 so that $100 \mu \mathrm{L}$ of each diluted serum sample was added in duplicate to the pre-coated plates. Positive and negative controls were added in duplicate to each plate. After 
Table 6 Values used as priors in the latent class analysis for sensitivity (Se) and specificity (Sp) of the western blot analysis (WB), the ID Screen ${ }^{\oplus}$ ELISA and the BIO K302 ELISA, respectively, together with the estimated alpha and beta parameters $(\alpha ; \beta)$ for the beta distribution of these priors

\begin{tabular}{lllll}
\hline Diagnostic test & Se & $\beta(a ; \beta)$ & Sp & $\beta(a ; \beta)$ \\
\hline WB & $0.72(0.16-0.96)$ & $1.8413 ; 1.3272$ & $0.90(0.56-1.00)$ & $6.895 ; 1.655$ \\
ID Screen ${ }^{\oplus}$ & $0.90(0.80-1.00)$ & $42.5732 ; 5.6192$ & $0.95(0.90-1.00)$ & $99.6983 ; 6.1946$ \\
BIO K302 & $0.48(0.30-0,65)$ & $11.1876 ; 12.0365$ & $0.96(0.90-1.00)$ & $128.4285 ; 6.3095$ \\
\hline
\end{tabular}

incubation for $1 \mathrm{~h}$ at $\mathrm{RT}$, the plates were washed three times with wash solution and $100 \mu \mathrm{L}$ of conjugate solution (HRP conjugated Protein G) diluted 1:50 was added to each well. The plates were again incubated for $1 \mathrm{~h}$ at RT (recommended by the manufacturer to be $21+/-$ $3{ }^{\circ} \mathrm{C}$ ) before washing three times followed by addition of $100 \mu \mathrm{L}$ of TMB reagent solution to each well. The plates were incubated $10 \mathrm{~min}$ at RT in the dark before the reaction was stopped with $50 \mu \mathrm{L}$ of stop solution $(1 \mathrm{M}$ phosphoric acid). The OD was measured at $450 \mathrm{~nm}$. The test was considered valid if the difference between the mean positive and the mean negative control was greater than 0.7 and the mean negative serum had an $\mathrm{OD}_{450}$ of less than 0.4. All serum samples were run in duplicate on separate plates and for each serum sample in each run an S/P \% was calculated as described above for the ID Screen ${ }^{\circ}$ ELISA according to manufacturers' instructions. The S/P \% for each sample for each run was again used to categorise the sample as positive or negative using the cut-off value provided by the manufacturer (positive if S/P \% > 37\%).

\section{Reporting of results}

Each of the six participating laboratories performed the two commercially available ELISAs, but only one laboratory (laboratory 3) performed the WB. A standardised result recording template was completed by each of the laboratories. Data was collated and statistically analysed using dedicated expertise at one of the participating laboratories.

\section{Statistical analysis Precision}

The ability of the two ELISA systems to consistently categorise the sample as positive or negative was evaluated by comparing the categorisation in each of the two duplicate runs for each sample at each of the six participating laboratories.

\section{Accuracy}

For each serum sample and ELISA, the mean S/P \% from the two duplicate runs were used to categorise the sample as positive and negative for each laboratory, again using the cut-off value provided by the two manufacturers. The results from the six different laboratories were then used to evaluate the diagnostic performance of each of the three tests for serodiagnosis of $M$. bovis. In the absence of a gold-standard reference test for $M$. bovis antibodies in cattle, a LCA using a Bayesian formulation was selected as the preferred method to estimate the diagnostic sensitivities $(S e)$ and specificities $(S p)$ of the three diagnostic tests [39-42]. The serum samples were separated into two subpopulations based on their origin from the afore-mentioned high-prevalence or the low-prevalence areas (Table 5).

The LCA was performed in OpenBUGS 3.2.2 rev 1063 (OpenBUGS, 2010-2011 Members of Open BUGS Project Management Group) using a Markov Chain Monte Carlo (MCMC) sampling algorithm (Gibbs sampling algorithm) to obtain a random sample from the joint posterior distribution of all model parameters. Informative prior beta distributions for $S e$ and $S p$ were estimated based on previous $M$. bovis serological and bulk tank milk (BTM) studies [10, 12, 17, 21], and the alpha and beta parameters for the beta distributions were estimated using the calculator on the EpiTools website [43]. The input values for the prior distributions are summarised in Table 6. In addition to the model with informative priors, a model with uniform distribution for all parameters was also applied $(\beta(1,1)$.

In the LCA, three MCMC chains with different initial values were compiled for 50,000 iterations of the model, discarding the first 15,000 iterations as the burn-in phase. A thinning of 1 in 10 was applied. The timeseries plots of the variables, the Gelman-Rubin diagnostic plots and the autocorrelation plots were all visually inspected for model evaluation. As estimation of $\mathrm{Se}$ and $S p$, the covariance between the three diagnostic tests, as well as the seroprevalence in each subpopulation of samples, the median of the posterior distribution was applied. As estimates of the $95 \%$ posterior credibility intervals for each variable, the 2.5 and 97.5 points were used.

\section{Supplementary information}

Supplementary information accompanies this paper at https://doi.org/10. 1186/s12917-019-2117-0.

Additional file 1. Table with the sample number, the S/P \% for the two duplicate runs (duplicate 1 and 2, respectively) as well as the categorisation (cat.) based on the cut-off suggested by the manufacturer for the in total 72 duplicates where the categorisation was not preserved between the two runs. 


\section{Abbreviations}

BTM: Bulk tank milk; ELISA: Enzyme-linked immunosorbent assay; LCA: Latent class analysis; MCMC: Markov Chain Monte Carlo; OD: Optical density; PBS: Phosphate buffered saline; PCl: Posterior credibility intervals; PCR: Polymerase chain reaction; RT: Room temperature; S/P \%: Sample-topositive percentage; Se: Sensitivity; Sp: Specificity; TMB: Tetramethylbenzidine; WB: Western blot analysis

\section{Acknowledgements}

The authors gratefully acknowledge Agnès Tricot (ANSES), Adélie Colin (ANSES), Maja Persson (SVA) and Nella Vähänikkilä (Evira) for performing ELISA analyses, the Laboratory Services Division, APHA for provision of serum and Ann-Kristin Nyman, Växa Sverige, Sweden, for excellent advice on statistical analysis.

\section{Authors' contributions}

AR, AA, HJW, SP and FT designed and HJW organized the ring trial. AA, HJW $B S, A R, S P, T A, K T L, J K, P G$ and FT acquired the data and AMA did the statistical analysis. AMA, AA, HJW, AR and FT drafted the manuscript. All authors read and approved the final manuscript.

\section{Funding}

This study was carried out as a Joint Scientific Activity funded by the CoVetLab consortium (www.covetlab.org). The Funder had no role in study design, data collection and interpretation, or in the decision to submit the work for publication

\section{Availability of data and materials}

All datasets supporting our findings are available from the corresponding author on reasonable request.

\section{Ethics approval and consent to participate}

The serum panel was collated only for the purpose of performing this study. In Finland, serum samples were submitted for diagnostic purposes to the Finnish Food Authority with a consent from the farmers participating in a research project "Mycoplasma bovis in dairy herds". Samples for the purpose of health screening or disease treatment fall under the Finnish Animal Diseases Act (441/2013) and do not require further ethical approval, as they are intended to maintain the well-being of animals. In France, serum samples were acquired for diagnosis purpose with a consent from the farmers to reuse them for non-commercial, research activities. Sample collection for diagnosis purpose in France does not require approval by our local ethics committee (Anses/ENVA/UPEC). In the Netherlands, serum sampling of the calves was granted an exemption from requiring ethics approval by the institutional Animal Experiment Commission "Dier Experimenten Commissie (DEC) Lelystad $(2,013,111 . b)^{\prime \prime}$, because sampling was performed for diagnostic purposes. Consent for participation was obtained verbally from the farmers. In Sweden, serum sampling of cattle is systematically performed each year for disease screening on behalf of the Swedish Board of Agriculture, and a consent to use a subset of these samples in the present study was given by the Board. Use of such serum samples do not demand ethical permission according to Swedish national law, as stated in the code of statute SJVSF 2019:9 (http://www.jordbruksverket.se). This exemption from ethical permission was confirmed by Djurskyddsorganet (the Animal Welfare Body, SVA, Sweden). All Swedish cattle herds are affiliated to a voluntary or mandatory surveillance program, as regulated by SJVFS 1993:42 and SJVFS 2003:31 (http://www.jordbruksverket.se), respectively. Consent by each farmer is given by registration to one of these surveillance programs. In the UK, serum samples were submitted to APHA for diagnostic purposes. Samples from veterinary interventions such blood sample collection for the purpose of health screening or disease treatment fall under the Veterinary Surgeons Act 1966 and do not require further ethical approval, as they are intended to maintain the well-being of animals.

\section{Consent for publication}

Not applicable.

\section{Competing interests}

The authors declare that they have no competing interests.

\section{Author details}

${ }^{1}$ National Veterinary Institute (SVA), Uppsala, Sweden. ${ }^{2}$ Wageningen Bioveterinary Research, P.O. Box 65, 8200, AB, Lelystad, the Netherlands. ${ }^{3}$ Animal and Plant Health Agency (APHA), Surrey, UK. ${ }^{4}$ Finnish Food Authority, Kuopio, Finland. ${ }^{5}$ National Veterinary Institute, Technical University of Denmark, Kgs Lyngby, Denmark. 'Eniversité de Lyon, Anses, Laboratoire de Lyon, UMR Mycoplasmoses des ruminants, Lyon, France.

Received: 21 May 2019 Accepted: 27 September 2019

Published online: 25 October 2019

\section{References}

1. Calcutt MJ, Lysnyansky I, Sachse K, Fox LK, Nicholas RAJ, Ayling RD. Gap analysis of Mycoplasma bovis disease, diagnosis and control: an aid to identify future development requirements. Transbound Emerg Dis. 2018; 65(Suppl 1):91-109.

2. Fox LK. Mycoplasma mastitis: causes, transmission, and control. Vet Clin North Am Food Anim Pract. 2012;28(2):225-37.

3. Nicholas RA. Bovine mycoplasmosis: silent and deadly. Vet Rec. 2011;168(17): 459-62.

4. Maunsell FP, Woolums AR, Francoz D, Rosenbusch RF, Step DL, Wilson DJ, Janzen ED. Mycoplasma bovis infections in cattle. J Vet Intern Med. 2011; 25(4):772-83.

5. Burki S, Frey J, Pilo P. Virulence, persistence and dissemination of Mycoplasma bovis. Vet Microbiol. 2015;179(1-2):15-22.

6. Vähänikkilä N, Pohjanvirta T, Haapala V, Simojoki H, Soveri T, Browning GF, Pelkonen S, Wawegama NK, Autio T. Characterisation of the course of Mycoplasma bovis infection in naturally infected dairy herds. Vet Microbiol. 2019;231:107-15.

7. Parker AM, Sheehy PA, Hazelton MS, Bosward KL, House JK. A review of mycoplasma diagnostics in cattle. J Vet Intern Med. 2018;32(3):1241-52.

8. Nicholas RA, Ayling RD. Mycoplasma bovis: disease, diagnosis, and control. Res Vet Sci. 2003;74(2):105-12.

9. Wisselink HJ, Smid B, Plater J, Ridley A, Andersson AM, Aspan A, Pohjanvirta T, Vähänikkilä N, Larsen H, Hogberg J, Colin A, Tardy F. A European interlaboratory trial to evaluate the performance of different PCR methods for Mycoplasma bovis diagnosis. BMC Vet Res. 2019;15(1):86.

10. Schibrowski ML, Barnes TS, Wawegama NK, Vance ME, Markham PF, Mansell PD, Marenda MS, Kanci A, Perez-Casal J, Browning GF, Gibson JS, Mahony TJ. The Performance of Three Immune Assays to Assess the Serological Status of Cattle Experimentally Exposed to Mycoplasma bovis. Vet Sci. 2018; 5(1):27.

11. Brank M, Le Grand D, Poumarat F, Bezille P, Rosengarten R, Citti C. Development of a recombinant antigen for antibody-based diagnosis of Mycoplasma bovis infection in cattle. Clin Diagn Lab Immunol. 1999;6(6): $861-7$.

12. Wawegama NK, Browning GF, Kanci A, Marenda MS, Markham PF. Development of a recombinant protein-based enzyme-linked immunosorbent assay for diagnosis of Mycoplasma bovis infection in cattle. Clin Vaccine Immunol. 2014;21(2):196-202.

13. Liberal MHT, Boughton E. Comparison between enzyme linked immunosorbent assay, disc film inhibition and complement fixation tests for the diagnosis of Mycoplasma bovis. Pesq Agrop Brasileira. 1994;29:823-30.

14. Robino P, Alberti A, Pittau M, Chessa B, Miciletta M, Nebbia P, Le Grand D, Rosati S. Genetic and antigenic characterization of the surface lipoprotein P48 of Mycoplasma bovis. Vet Microbiol. 2005;109(3-4):201-9.

15. Fu P, Sun Z, Zhang Y, Yu Z, Zhang H, Su D, Jiang F, Wu W. Development of a direct competitive ELISA for the detection of Mycoplasma bovis infection based on a monoclonal antibody of P48 protein. BMC Vet Res. 2014;10:42.

16. Sun Z, Fu P, Wei K, Zhang H, Zhang Y, Xu J, Jiang F, Liu X, Xu W, Wu W. Identification of novel immunogenic proteins from Mycoplasma bovis and establishment of an indirect ELISA based on recombinant E1 beta subunit of the pyruvate dehydrogenase complex. PLoS One. 2014;9(2):e88328.

17. Wawegama NK, Markham PF, Kanci A, Schibrowski M, Oswin S, Barnes TS, Firestone SM, Mahony TJ, Browning GF. Evaluation of an lgG enzyme-linked immunosorbent assay as a serological assay for detection of Mycoplasma bovis infection in feedlot cattle. J Clin Microbiol. 2016;54(5):1269-75.

18. Ayling RD, Gosney F, Hlusek M. Mycoplasma diagnostics, some results, and what we still don't know about Mycoplasma bovis disease. Cattle Practice. 2015;23:248-51. 
19. Ayling RD, Bashiruddin SE, Nicholas RA. Mycoplasma species and related organisms isolated from ruminants in Britain between 1990 and 2000. Vet Rec. 2004;155(14):413-6.

20. Parker AM, House JK, Hazelton MS, Bosward KL, Morton JM, Sheehy PA. Bulk tank milk antibody ELISA as a biosecurity tool for detecting dairy herds with past exposure to Mycoplasma bovis. J Dairy Sci. 2017:100(10):8296-309.

21. Nielsen PK, Petersen MB, Nielsen LR, Halasa T, Toft N. Latent class analysis of bulk tank milk PCR and ELISA testing for herd level diagnosis of Mycoplasma bovis. Prev Vet Med. 2015;121(3-4):338-42.

22. Register KB, Sacco RE, Olsen SC. Evaluation of enzyme-linked immunosorbent assays for detection of Mycoplasma bovis-specific antibody in bison sera. Clin Vaccine Immunol. 2013;20(9):1405-9.

23. Heller M, Berthold E, Pfutzner H, Leirer R, Sachse K. Antigen capture ELISA using a monoclonal antibody for the detection of Mycoplasma bovis in milk. Vet Microbiol. 1993;37(1-2):127-33.

24. Byrne WJ, Ball HJ, Brice N, McCormack R, Baker SE, Ayling RD, Nicholas RA. Application of an indirect ELISA to milk samples to identify cows with Mycoplasma bovis mastitis. Vet Rec. 2000;146(13):368-9.

25. von Schultz K. Utredning av ett utbrott av lunginflammation med Mycoplasma bovis i en svensk nötbesättning samt analys av antikroppar mot Mycoplasma bovis i tankmjölk från svenska besättningar. Uppsala: Sveriges lantbruksuniversitet, SLU (Swedish University of Agriculture); 2015.

26. Petersen MB, Krogh $K$, Nielsen LR. Factors associated with variation in bulk tank milk Mycoplasma bovis antibody-ELISA results in dairy herds. J Dairy Sci. 2016;99(5):3815-23.

27. Petersen MB, Wawegama NK, Denwood M, Markham PF, Browning GF, Nielsen LR. Mycoplasma bovis antibody dynamics in naturally exposed dairy calves according to two diagnostic tests. BMC Vet Res. 2018; 14(1):258.

28. Nekouei O, Stryhn H, VanLeeuwen J, Kelton D, Hanna P, Keefe G. Predicting within-herd prevalence of infection with bovine leukemia virus using bulktank milk antibody levels. Prev Vet Med. 2015;122(1-2):53-60.

29. Nielsen SS, Toft N. Bulk tank milk ELISA for detection of antibodies to Mycobacterium avium subsp. paratuberculosis: correlation between repeated tests and within-herd antibody-prevalence. Prev Vet Med. 2014;113(1):96-102.

30. Attalla SA, Seykora AJ, Cole JB, Heins BJ. Genetic parameters of milk ELISA scores for Johne's disease. J Dairy Sci. 2010;93(4):1729-35.

31. Petersen MB, Pedersen J, Holm DL, Denwood M, Nielsen LR. A longitudinal observational study of the dynamics of Mycoplasma bovis antibodies in naturally exposed and diseased dairy cows. J Dairy Sci. 2018;101(8):7383-96.

32. Perez-Casal J, Prysliak T, Maina T, Suleman M, Jimbo S. Status of the development of a vaccine against Mycoplasma bovis. Vaccine. 2017;35(22): 2902-7.

33. Becker CA, Thibault FM, Arcangioli MA, Tardy F. Loss of diversity within Mycoplasma bovis isolates collected in France from bovines with respiratory diseases over the last 35 years. Infect Genet Evol. 2015;33:118-26.

34. Ridley A, Hateley G. Mycoplasma bovis investigations in cattle. Vet Rec. 2018, 183(8):256-8.

35. Ter Laak EA, Wentink GH, Zimmer GM. Increased prevalence of Mycoplasma bovis in the Netherlands. Vet Q. 1992;14(3):100-4.

36. Poumarat F, Longchambon D, Martel JL. Application of dot immunobinding on membrane filtration (MF dot) to the study of relationships within " $M$. mycoides cluster" and within "glucose and arginine-negative cluster" of ruminant mycoplasmas. Vet. Microb. 1992;32(3-4):375-90.

37. Poumarat F, Le Grand D, Gaurivaud P, Gay E, Chazel M, Game Y, Bergonier D. Comparative assessment of two commonly used commercial ELISA tests for the serological diagnosis of contagious agalactia of small ruminants caused by Mycoplasma agalactiae. BMC Vet Res. 2012;8:109.

38. Marenda MS, Sagne E, Poumarat F, Citti C. Suppression subtractive hybridization as a basis to assess mycoplasma agalactiae and Mycoplasma bovis genomic diversity and species-specific sequences. Microbiol. 2005; 151(Pt 2):475-89.

39. Hui SL, Walter SD. Estimating the error rates of diagnostic tests. Biometrics. 1980;36(1):167-71.

40. Toft N, Innocent GT, Gettinby G, Reid SW. Assessing the convergence of Markov chain Monte Carlo methods: an example from evaluation of diagnostic tests in absence of a gold standard. Prev Vet Med. 2007;79(2-4): 244-56.
41. Toft N, Akerstedt J, Tharaldsen J, Hopp P. Evaluation of three serological tests for diagnosis of Maedi-Visna virus infection using latent class analysis. Vet Microbiol. 2007;120(1-2):77-86.

42. Branscum AJ, Gardner IA, Johnson WO. Estimation of diagnostic-test sensitivity and specificity through Bayesian modeling. Prev Vet Med. 2005; 68(2-4):145-63.

43. Sergeant ESG. Epitools epidemiological calculators. Ausvet Pty Ltd; 2019. Available at: http://epitools.ausvet.com.au.

\section{Publisher's Note}

Springer Nature remains neutral with regard to jurisdictional claims in published maps and institutional affiliations.
Ready to submit your research? Choose BMC and benefit from:

- fast, convenient online submission

- thorough peer review by experienced researchers in your field

- rapid publication on acceptance

- support for research data, including large and complex data types

- gold Open Access which fosters wider collaboration and increased citations

- maximum visibility for your research: over $100 \mathrm{M}$ website views per year

At BMC, research is always in progress.

Learn more biomedcentral.com/submissions 